\title{
Towards even cleaner Diesel engines: Contribution of 3D CFD tools
}

\author{
B. Reveille' ${ }^{1}$ A. Kleemann ${ }^{1}$ and S. Jay ${ }^{1}$ \\ 1 Institut français du pétrole, 1 et 4, avenue de Bois-Préau, 92852 Rueil-Malmaison Cedex - France \\ e-mail: benjamin.reveille@ifp.fr - andreas.fleemann@ifp.fr - stephane.jay@ifp.fr
}

Résumé - Vers des moteurs Diesel encore plus propres : contribution des outils de simulation 3D — Les outils de Mécanique des Fluides Numérique (MFN) sont devenus essentiels à la recherche sur les moteurs Diesel. En effet, ils permettent d'appréhender les phénomènes en jeu alors même que les procédés de combustion deviennent de plus en plus complexes afin de répondre à des attentes diamétralement opposées : une réglementation des émissions polluantes de plus en plus sévère et l'agrément de conduite (puissance et couple en croissance perpétuelle) qu'attend le client de son véhicule. Cependant, les outils de MFN ne peuvent être plus précis que leurs sous-modèles, raison pour laquelle la modélisation de l'injection, de l'auto inflammation et de la combustion sont en perpétuelle évolution afin d'être en adéquation avec les phénomènes rencontrés durant les essais au banc moteur. Cette adéquation permet à la simulation tridimensionnelle de contribuer activement aux divers projets de recherche sur les moteurs Diesel à l'IFP.

De nouveaux modèles ont été développés pour la combustion et l'auto-inflammation basse température afin de reproduire fidèlement la combustion HCCI. Récemment, l'IFP a proposé un nouveau concept de combustion bimode à faibles émissions de NOx et suies nommé NADI ${ }^{\mathrm{TM}}$ qui passe de la combustion HCCI aux charges partielles à la combustion conventionnelle pour les fortes charges. Forte des récents développements, la MFN a fortement contribué au développement du concept NADI ${ }^{\mathrm{TM}}$ de par sa capacité à analyser les phénomènes en jeu et d'extraire des axes de progression dans les 2 modes de combustion. De plus, la MFN s'est avérée un excellent outil pour le portage du concept sur une multitude d'applications. Les simulations qui peuvent maintenant être réalisées sur une très large plage de fonctionnement moteur (jusqu'à 60 \% d'EGR) permettent de concevoir et d'optimiser toutes les générations de moteurs Diesel Injection Directe pour des applications véhicules légers ou poids lourds. Les effets de paramètres tels que la géométrie du piston, le système d'injection, l'aérodynamique interne et le taux d'EGR peuvent être cartographiés afin d'en extraire la configuration qui réponde au mieux aux objectifs.

\footnotetext{
Abstract - Towards even cleaner Diesel engines: Contribution of 3D CFD tools - Three-dimensional Computational Fluid Dynamics (CFD) tools have become essential for research on Diesel engines. Indeed they help grasp the basic phenomena at stake, as combustion processes get more and more complex in order to comply with conflicting demands: more stringent emission standards and customer desire for "fun-to-drive" vehicles, i.e. higher torque and power outputs. CFD tools are however only as accurate as their physical submodels. That is why at IFP, injection, combustion and auto-ignition models are constantly evolving in order to keep CFD in pace with test bench innovations and demands. Such a close follow-up of CFD tools enables $3 D$ computations to contribute actively in all IFP research projects on DI Diesel engines.
} 
New combustion and low temperature auto-ignition models were developed, enabling an accurate representation of Homogeneous Charge Compression Ignition (HCCI) process. Lately, IFP has developed a near zero NOx and particulate combustion process, the Narrow Angle Direct Injection $\left(N A D I^{T M}\right)$ concept, a dual mode engine application switching from HCCI combustion at part load to conventional Diesel combustion at full load. The new capabilities of CFD tools support the development of the NADITM concept since they enable the comprehension of the phenomena at stake in both operating modes, provide guidelines to optimize the engine configuration, and help port the concept from an application to another. Simulations, which are now possible for the entire operating range including Exhaust Gas Recirculation (EGR) rates up to 60\%, successfully help to design and optimize all generations of DI Diesel engines for passenger cars and heavy duty vehicles. The effects of combustion system parameters such as piston bowl geometry, Fuel Injection System (FIS), in-cylinder fluid motion or EGR rates can be mapped in order to determine the best configuration matching the objectives.

\section{INTRODUCTION}

The latest technological evolutions of the DI Diesel engine have given it a major role in the European market as an economical, $\mathrm{CO}_{2}$ friendly, and "fun-to-drive" powertrain solution. However, with emission standards getting tougher and tougher, the challenges facing the Diesel engine imply more and more research, in order to maintain and/or strengthen the DI Diesel engine's position as other clean powertrain solutions start to emerge. In this constant quest for Diesel engine improvement, CFD tools are put to contribution as an important link in the development chain. Indeed, not only do they allow a better understanding of the various phenomena at stake inside a combustion chamber, they also stand out as increasingly reliable tools, for cost and time saving, during the development phase of new powertrains.

At IFP, CFD solvers and physical submodels are constantly evolving and allow researchers to improve their knowledge and comprehension of current solutions. Therefore it allows them to take the extra step and to explore new concepts which may potentially be integrated in future generations of powertrains, be they for passenger cars or heavy duty applications.

\section{KEEPING CFD TOOLS UP TO DATE}

Diesel engines have seen the greatest evolution in the past years with the shift from indirect to direct injection (DI), the development of new injector technologies-Common Rail (CR) - , the increase of injection pressure and the growing interest for new and cleaner combustion modes. CFD tools have found their place in the development chain as a way to better understand and fully benefit from these technological leaps by using them at their utmost. In order to maintain their position, they must be kept in pace with test bench investigations. That is why they must be reliable tools for the investigation of fields where there is not much background information. Simulation being as accurate as its least accurate submodel, all the phenomena at stake during an engine cycle must be correctly accounted for and in perpetual improvement. In Diesel engines the most important phases are injection/spray, auto-ignition, combustion and pollutant formation. For each of these events IFP has developed dedicated models in order to reproduce as accurately as possible the physics inside the combustion chamber. Work on pollutant formation models is intensifying as they come last in the submodel chain and have therefore seen great improvement of all previous elements giving them more room for improvement.

\subsection{Transient Injection Condition model}

Previous studies [1-3] have shown that spray characteristics such as spray cone angle, spreading angle, injection speed, discharge coefficient and droplet size distribution vary in time during the opening, steady-state and closing phases of a high pressure in-cylinder injection, mainly because of the development of cavitation inside the injector. CFD inside Diesel injectors using the CAVIF Code [4] has helped develop the TIC model [5]: a new injection model able to take into account such Transient Injection Conditions. These parameters are a function of the cavitation number (Ncavit), the geometrical characteristics (nozzle hole diameter, spray cone angle and mean spreading angle), and the injection rate.

$$
\text { Ncavit }=\frac{P_{i n j}-P_{c y l}}{P_{c y l}}: \text { cavitation number }
$$

These transient injection conditions have simplified the engineer's work as the effect of cavitation on the discharge coefficient is now taken into account explicitly. The only remaining inputs needed are provided directly by the test bench: the injection rate, hole diameter and injection pressure. Figure 1 illustrates the quality of the results obtained using this new model for pressure cell computations. 

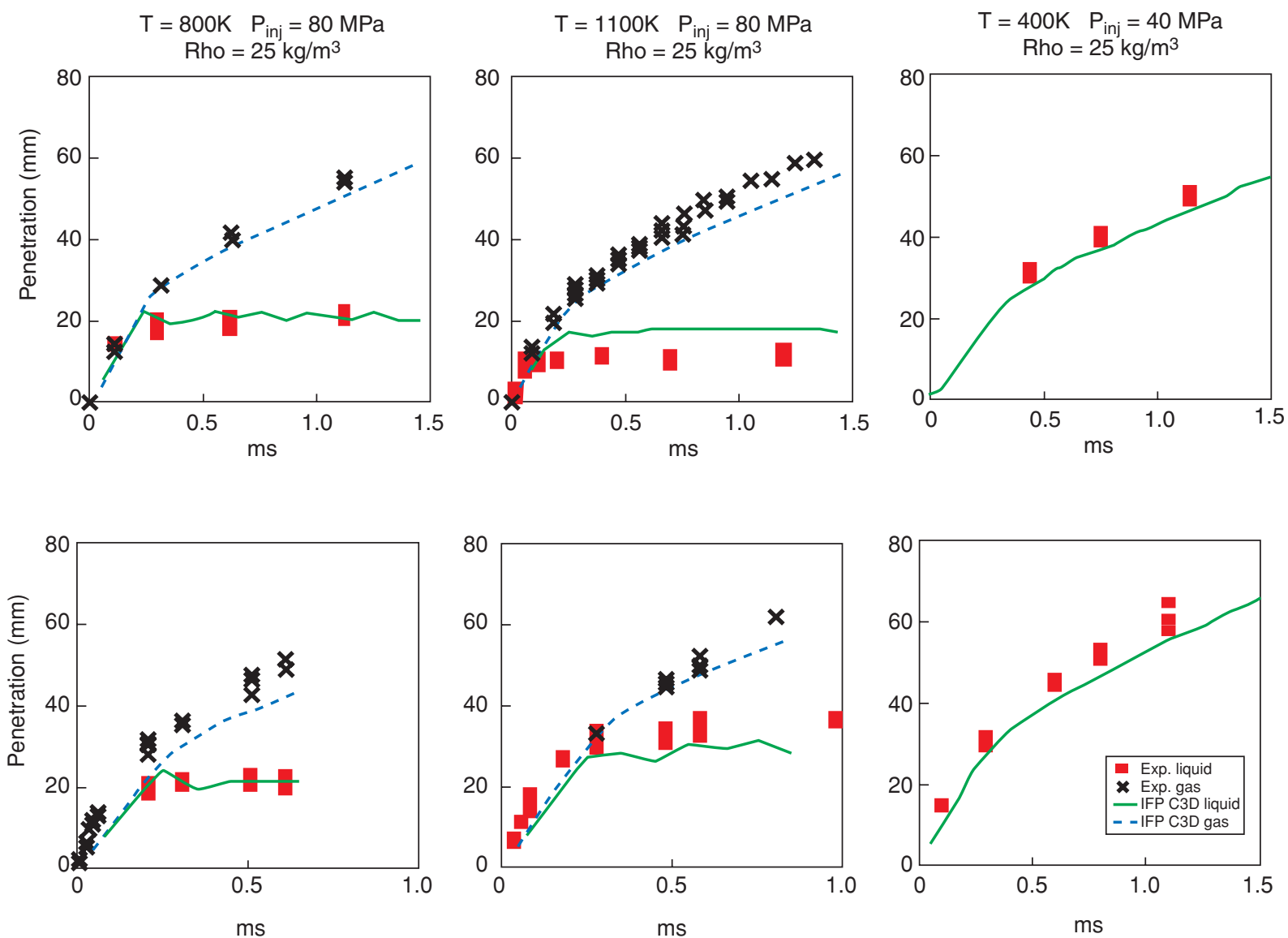

Figure 1

High pressure cell results with TIC injection model.

\subsection{ECFM3Z Combustion Model}

The 3 Zones Extended Coherent Flame Model (ECFM3Z) has been recently developed at IFP for both SI and Diesel applications. This model is based on the ECFM model [20] devoted to SI combustion, which has been extensively validated [20]. The ECFM3Z model is thoroughly described in [21] therefore only a brief description of this model is given here.

Compared to the ECFM model, the ECFM3Z model adds a description of the state of mixing between fuel and air by splitting the computational cell into three mixing zones (Fig. 2): region $\mathrm{F}$ contains only pure fuel, region $\mathrm{M}$ contains a mixture of fuel and air and region A contains only air plus possible EGR. During injection, the evaporation of the spray droplets leads to a source term for mass in region $\mathrm{F}$. The fuel in region $\mathrm{F}$ begins to mix with the air+EGR of region $\mathrm{A}$ and forms a mixture in region $\mathrm{M}$. It is assumed that the characteristic mixing time depends on the characteristic time scale of the turbulence:

$$
\tau_{m}=f\left(\frac{k}{\varepsilon}\right)
$$

The air+EGR-fuel can then auto-ignite in region M. When the auto-ignition delay is reached (see below for auto-ignition model description), combustion in region $\mathrm{M}$ starts thereby dividing it into two zones: a fresh and a burnt gas zone (referenced as $\mathbf{M}^{\mathrm{u}}$ and $\mathrm{M}^{\mathrm{b}}$ in Fig. 2). As the fresh gases are oxidized by auto-ignition, the hot products formed are added to region $\mathrm{M}^{\mathrm{b}}$.

The pure fuel and air + EGR of regions F and A carry on mixing in region $\mathrm{M}$ after the auto-ignition process has begun. In this case, part of this mixture goes into the fresh gas region $\mathrm{M}^{\mathrm{u}}$ and the other in the burnt gas region $\mathrm{M}^{\mathrm{b}}$. In the latter region, we assume that fuel and air burn as in a diffusion flame since the reaction rate is essentially controlled by mixing.

As the oxidation process continues, the formation of pollutants (soot and $\mathrm{NO}_{\mathrm{x}}$ ) is taken into account in region $\mathrm{M}^{\mathrm{b}}$. The soot formation is described by the PSK (Phenomenological Soot Kinetics) model using a homogeneous reactor approach based on a ten reactions global kinetic mechanism presented in [23] while the $\mathrm{NO}_{\mathrm{x}}$ formation is described by the extended Zeldovich mechanism [25], state of the art model for industrial CFD codes for such applications. As these 


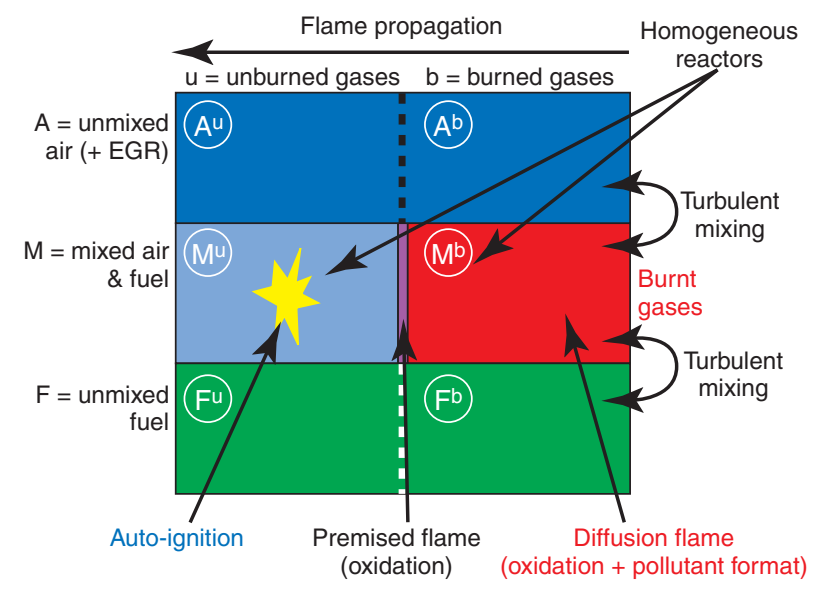

Figure 2

Description of the ECFM3Z combustion model.

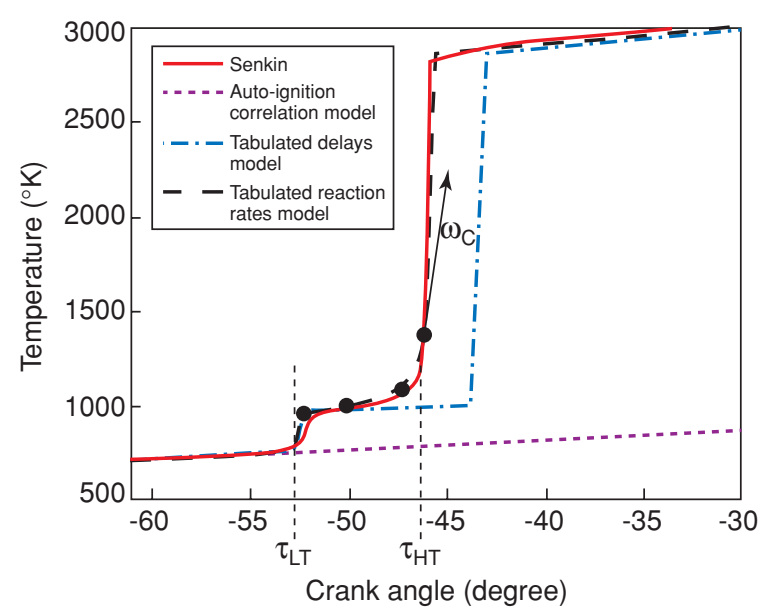

Figure 3

Temperature profiles obtained with the various models and complex chemistry calculation code (solid line). processes highly depend on the local temperature, equilibrium kinetics are carried out in this region in order to evaluate accurately the burnt gas temperature.

The ECFM3Z model, coupled with the spray model has proven quite effective for the simulation of conventional DI combustion systems [18]. However, due to the growing interest in HCCI combustion as an effective way to reduce raw emissions, tests were performed and showed that the existing AI model was unfit for such situations. The next step was to develop an AI model that would allow to explore the pros and cons of HCCI combustion, that is a model capable of reproducing the so-called cool flame effect or low temperature oxidation.

\subsection{Auto-Ignition Model: Delay Library with Cool Flame Effect}

In practical applications, especially for new low emissions combustion concepts such as HCCI engines, cool flames can be encountered. They are characterized by a first rapid increase of temperature (Favre average of the progress variable $\tilde{c}$ goes from 0 to a small fraction $C_{1}$ ) after a delay $\tau_{L T}$ has been reached, followed by a slow down of reactions until the main delay $\tau_{H T}$ is reached (see Fig. 3).

The first auto-ignition models used in ECFM3Z only considered the main delay $\tau_{H T}$ which lead to a systematic over-prediction of delays when cool flames occurred. A double delay model [6] was then proposed which greatly improved the results. In this model, the heat released during the cool flame period $\left(\tau_{L T}<t<\tau_{H T}\right)$ was not represented. As the auto-ignition process after delay $\tau_{L T}$ is very dependent on thermodynamic conditions (pressure and temperature increase), this still leads to an over-prediction of the main delay. It was concluded that the heat release observed after the delay $\tau_{L T}$ in the experiment had to be included in the model.

Based on this conclusion, a new auto-ignition model was proposed and extensively described in [29], which we present here briefly. This model relies, like the double delay model [6], on the post-processing of tabulated temperature profiles issued from complex chemistry calculations. The autoignition database has been generated with the Senkin code [8] which is part of the Chemkin package [9]. Since Diesel fuel composition is complex and no mechanism exists to model it, n-heptane has been chosen as the reference fuel. In the conditions corresponding to the present engine simulations, it was shown that n-heptane gives similar results to more complex surrogate fuels, even for diluted charges. For instance, n-decane/alpha-methylnaphthalen mixture with a molar composition of 70/30 has a calculated cetane number $\mathrm{CN}=54$ close to the n-heptane cetane number. This mixture and n-heptane behaves similarly for high temperature conditions. As described in [7], these two fuels behave differently for low temperature conditions. Despite dilution effects and the occurence of some cool flames (well reproduced by the nheptane mechanism), the charge is not cool enough in the present engine simulations with late injection strategies to make these differences significant. In [7] these two fuels are compared in engine simulations involving split injection strategies. The mechanism for this fuel is issued from the DCPR laboratory (Département de Chimie Physique des Réactions, $C N R S$, Nancy) and has been generated with an automatic algorithm for linear alcane oxidation proposed by [10]. The database has been built for the same set of thermodynamic conditions $\left(\mathrm{T}_{0}, p_{0}, \phi_{0}, X_{\text {res }}\right)$ as used in [6] at constant pressure. The model parameters are determined through post-processing and linearly interpolated in each 3D computational cell according to local thermodynamic conditions $\left.\mathrm{T}^{\mathrm{u}}, p, \phi, X_{r e s}\right)$. 


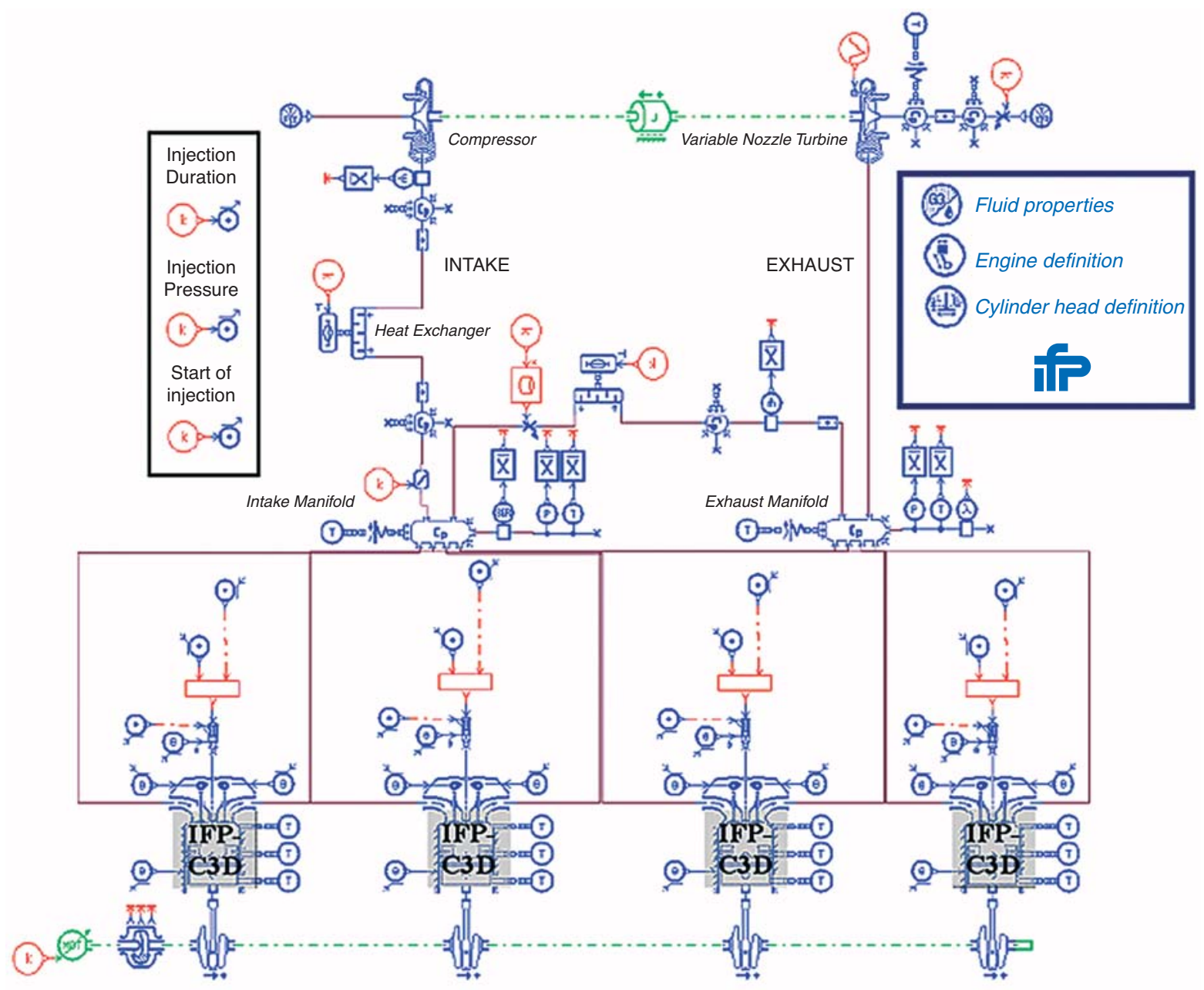

Figure 4

Integration and coupling of IFP-C3D with other libraries in AMESim.

This model permits to compute auto-ignition processes in both low and high temperature conditions. A comparison between the old auto-ignition correlation model [27, 28], the double delay method and the present model [29] on a fast compression machine case with a cool flame is presented in Figure 3. Both are compared with the temperature profile obtained with a Senkin calculation at constant volume with an initial temperature of $750 \mathrm{~K}$ in the same operating conditions $\left(\phi=1 ., X_{\text {res }}=10 \%\right)$. It can be seen that the single delay AI model fails to predict AI. The double delay model correctly predicts $\tau_{L T}$ but the main delay $\tau_{H T}$ is overestimated. Finally, the tabulated reaction rates model accurately reproduces the complex chemistry results.

\subsection{New CFD Software}

As the supercomputing world evolves towards the democratization of "low cost" super-scalar machines, IFP has developed a new parallel hexahedral unstructured CFD solver,
IFP-C3D, adapted to such computing platforms/architectures [1], [12-16]. In order to lower/shorten the development cost/time, the OPEN-MP paradigm was chosen for parallelization. This paradigm allows to mainly work on CPU time consuming routines and also ensures portability on SMP machines, workstations and PCs.

All submodels developed at IFP [17, 19], are now integrated into IFP-C3D which has become the new submodel development platform. The integration of IFP-C3D as the 3D Combustion library of AMESim ${ }^{\circledR}$ [26] (Advanced Modeling Environment for the Simulation of engineering systems) will allow coupling between 3D and 1D as illustrated in Figure 4.

\section{DESIGNING EVEN CLEANER DIESEL ENGINES}

All model improvements have a repercussion on today's engines as they allow to represent the combustion process with more accuracy. The best example is the benefits IFP has 
gained from the new auto-ignition delay libraries with cool flame effect. It is now possible to better understand the effect of EGR, and injection strategies, be it for conventional or HCCI combustion. These new capabilities are to be added to those already "in production" when it comes to combustion chamber design and optimization (such as piston bowl design, flow motion etc.).

\subsection{New Engine Concepts}

Thanks to the cool flame capability of the new AI model, it has been possible to investigate/develop concepts using all available combustion modes. The best example is HCCI combustion and more specifically, IFP's Narrow Angle Direct Injection (NADI ${ }^{\mathrm{TM}}$ ) concept using $\mathrm{HCCI} /$ Zero $\mathrm{NO}_{\mathrm{x}}$ combustion modes at part load and conventional combustion at full load.

\subsubsection{Early Homogenization in Traditional Direct Injection Engines}

Simulations were done which consisted in obtaining $\mathrm{HCCI}$ combustion through early homogenization in conventional combustion systems. The engine used is a 2.2 liter I4. Target operating point is 5 bar IMEP at $1400 \mathrm{rpm}$ using about $50 \%$ EGR. Early homogenization implied using multiple injections (up to 6) from 60 cad (crank angle degrees) bTDC (before Top Dead Center) to TDC. For the earliest injection timing the injector's minimal quantity was injected $\left(2 \mathrm{~mm}^{3}\right)$ and then the quantities grew according to in-cylinder temperature and pressure as illustrated in Figure 5, the aim being to minimize spray penetration for the very early injections to avoid wall impingement

Results showed that wall wetting and oil diluting were however unavoidable. Indeed Figure 6, Figure 7 and Figure 8 show the first and second injections heavily impacting the cylinder liner, the third stopping barely before impingement. The forth impacts the piston and the next 2 injections take place in the piston bowl. Liquid film is formed on the cylinder liner as illustrated by the spray particles (Lagrangian film model) that cling to the cylinder liner and are scraped by the piston ring. Results that went to show that early homogenization was unfeasible production wise although the mixture formation and combustion were quite good.

The NADI ${ }^{\mathrm{TM}}$ concept seemed a more interesting path as the narrow spray cone angle reduced/pushed back the wall wetting limits.

\subsubsection{NADI $^{\mathrm{TM}}$ Concept}

The NADI ${ }^{\mathrm{TM}}$ concept [30], being a dual mode concept, uses conventional combustion mode at full load and HCCI combustion at part load. High EGR levels combined with specific injection strategies were used in order to obtain the best emission levels possible at part load. CFD was used to optimize the combustion chamber geometry as a compromise between part and full load behavior.

\section{Optimizing the combustion system for full load}

The use of a narrow spray cone angle and conventional combustion for full load proved quite a challenge, which CFD helped to address. As illustrated in [30] simulation helped increase power. To do so, piston bowl design and flow motion variations were performed at 2000 and 4000 RPM so as to understand their influence on mixture formation, autoignition delay and combustion efficiency, considering injection characteristics and in-cylinder peak pressure constraints.

Piston bowl reentrant level is one of the many piston bowl design variations performed in order to optimize the combustion chamber at full load. For each reentrant studied, the effect of flow motion (swirl) were also examined. The results

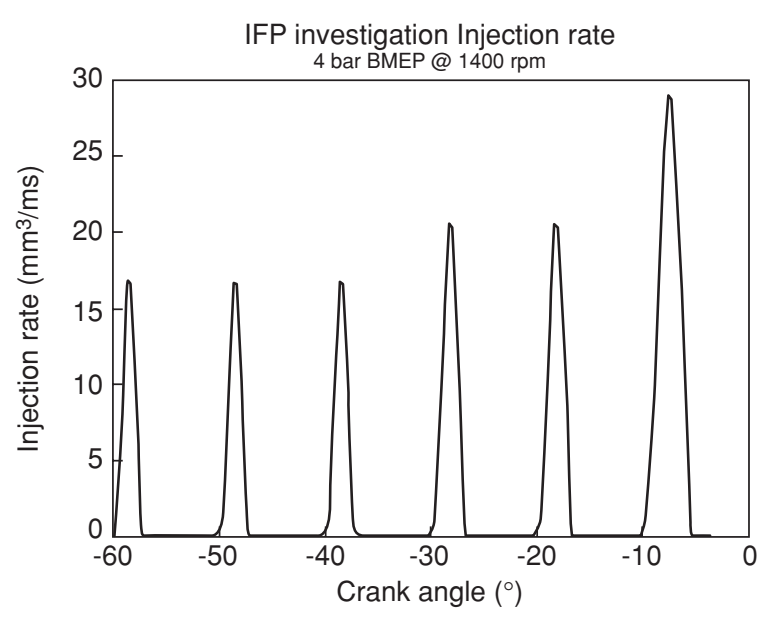

Figure 5

Early homogenization injection rate.

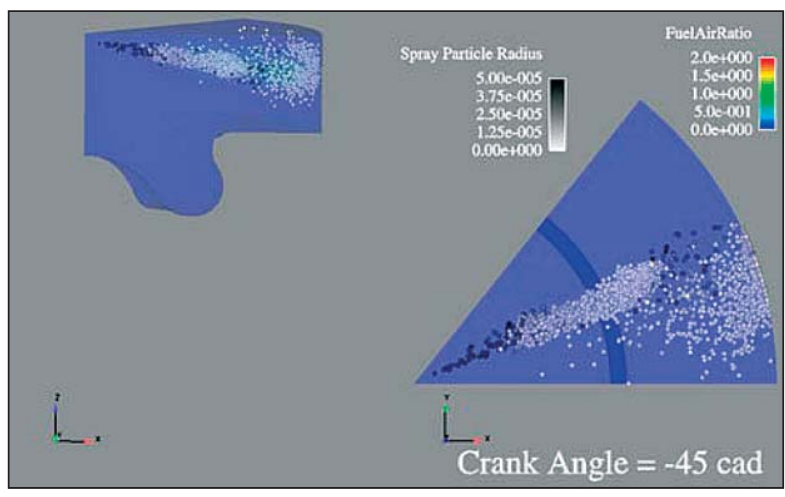

Figure 6

First injection impacting the cylinder liner. 


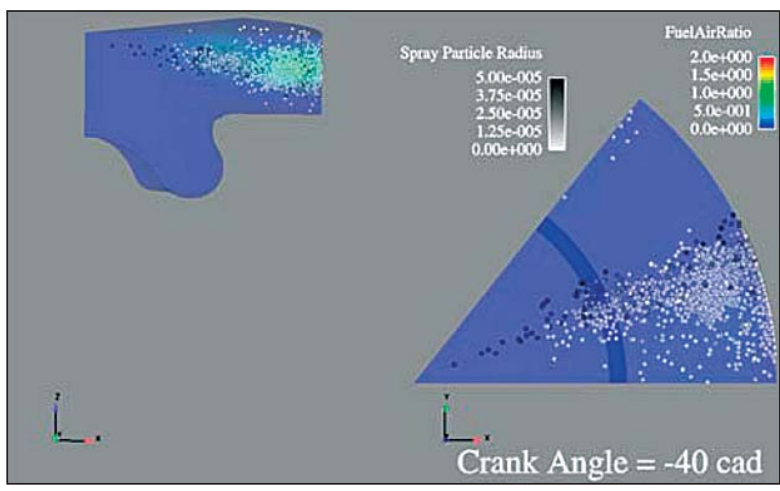

Figure 7

Second injection impacting the cylinder liner.

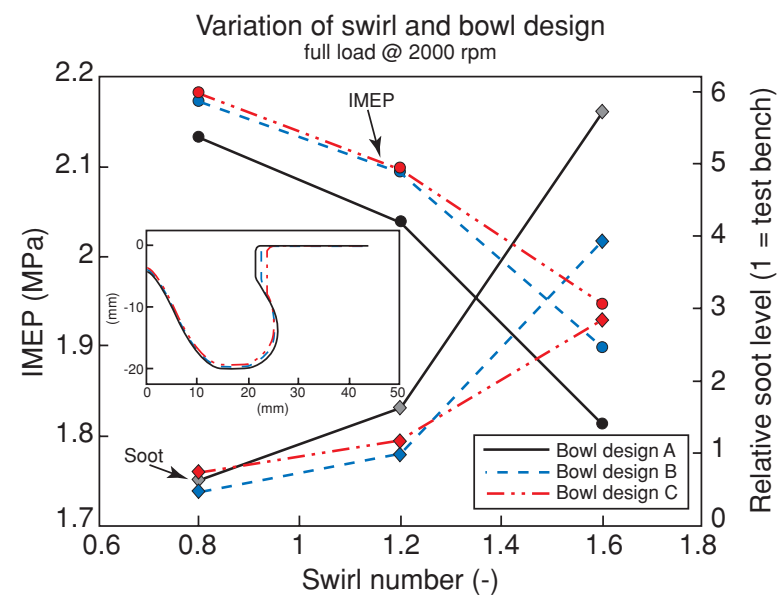

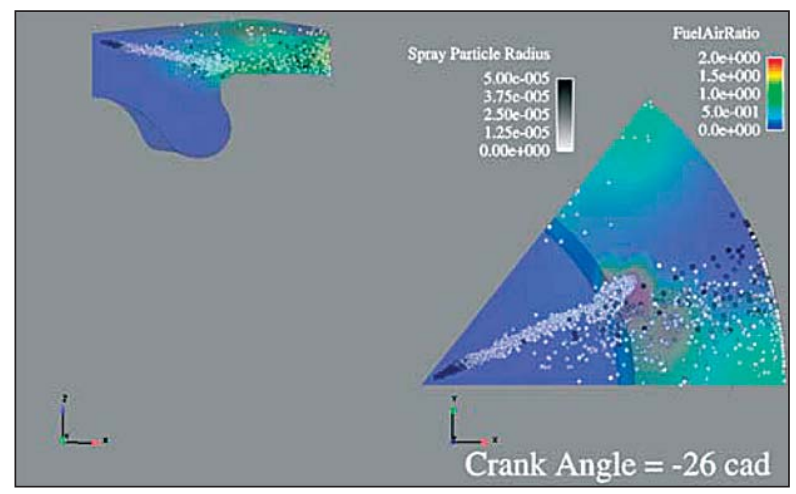

Figure 8

Third injection impacting the piston.

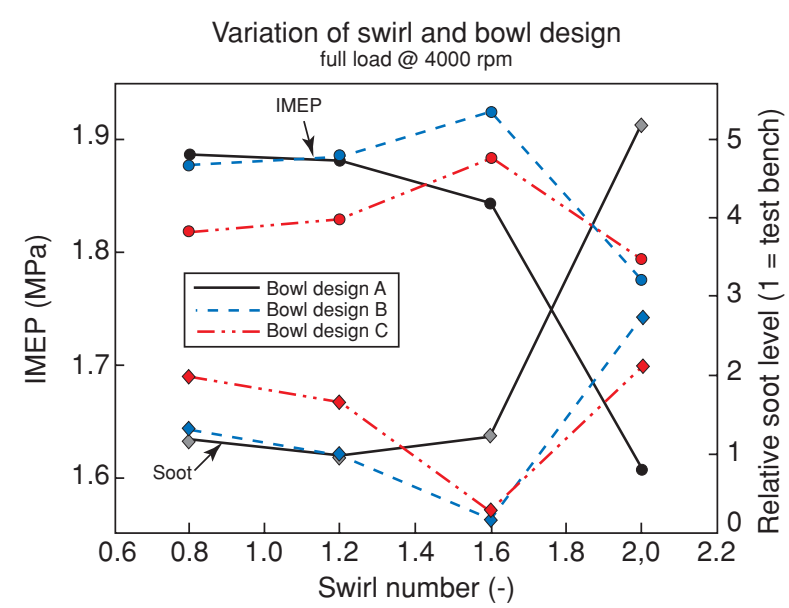

Figure 9

Power and Soot levels as a function of swirl and piston bowl design at 2000 and 4000 RPM full load .

of the calculations in terms of IMEP and soot level can be seen in Figure 9, for 3 different bowls with reentrant rates varying from $5 \%$ to $17 \%$, and for swirl numbers varying from 0.8 to 2.0 .

Concerning the influence of piston bowl design, our extensive calculations at two different engine speeds proved to be helpful to determine an optimal reentrant rate for the piston bowl. As a matter of fact, we observed that at 2000 RPM, highly increasing the reentrant rate leads to a loss of performance, in terms of IMEP and soot level (independently of the swirl level). At this engine speed, it appears that the extraction of the fuel is hampered by a too high reentrant level. The bowl with the smallest reentrant has quite the same performances as bowl B (with the intermediate reentrant).

On the contrary, we can see that at 4000 RPM the performances of bowl $\mathrm{C}$ (with the smallest reentrant rate) are lower than those of the other bowls from smaller swirl values. As it can be seen in Figure 10, we were able to explain why the reentrant level must not be too low for NADITM chambers: the fuel's extraction from the bowl requires a certain level of reentrant to fully benefit from the spray wall guiding. Without a reentrant, the fuel remains in the bowl thus the air in the squish area is not optimally used for combustion.

These calculations at full load allowed us to highlight and comprehend the importance of a well-adapted geometry for the NADI ${ }^{\mathrm{TM}}$ chamber; to fully benefit from the special shape of the piston bowl, an optimal spray wall guiding is necessary. In our case, given the injector used and maximum peak in-cylinder pressure, it seems that an optimal reentrant is obtained with bowl B as a trade-off between 2000 and 4000 RPM. 


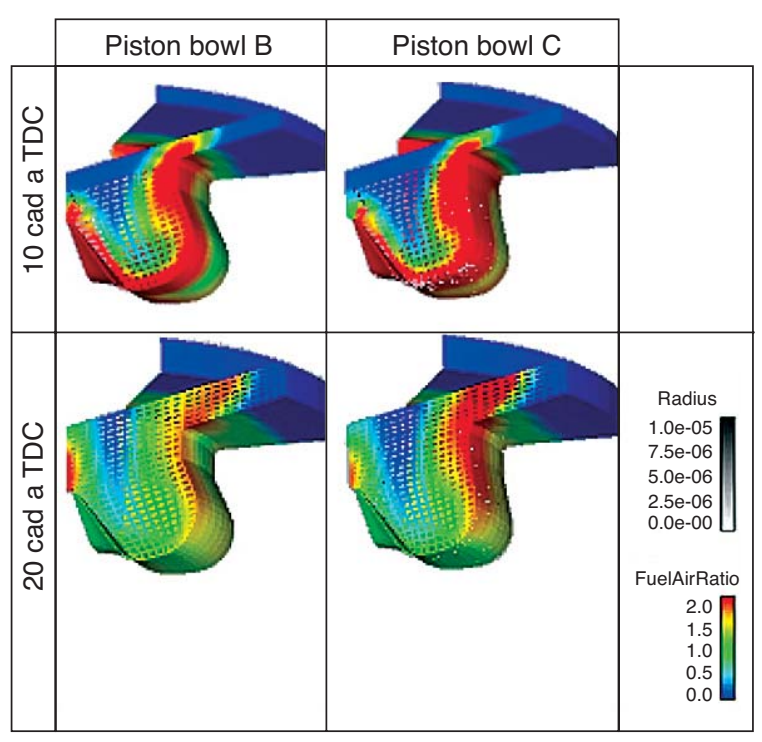

Figure 10

Effect of Piston bowl design on mixture formation, fuel extraction from the bowl and combustion at 4000 RPM for a swirl level of 1.2.

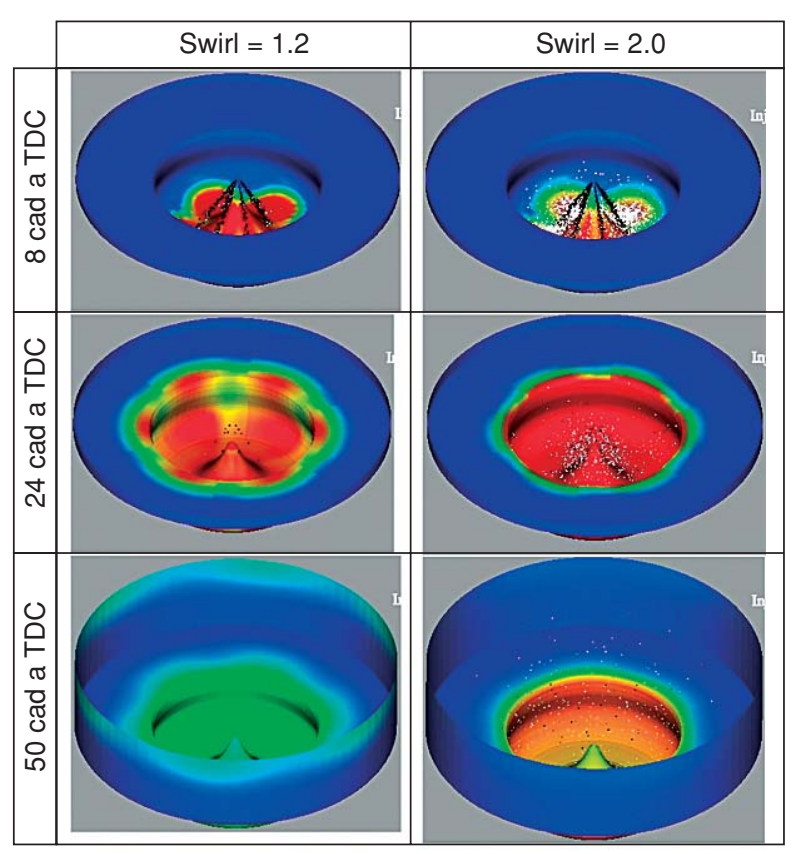

Figure 11

Effect of Swirl on mixture formation, fuel extraction from the bowl and combustion at 4000 RPM.

If we now look at the influence of flow motion on the performances of the NADI ${ }^{\mathrm{TM}}$ chamber, we can see from $3 \mathrm{D}$ calculation results in Figure 9 that the less swirl in the chamber, the better the combustion efficiency at full load.
As illustrated in Figure 11, if the swirl motion is too high, the injected fuel cannot be efficiently extracted from the piston bowl. The air in the combustion chamber is then not fully used and the combustion is not optimal (as it can be seen in the localisation and high level of soot produced at the exhaust valve opening cf. Fig. 12).

\section{Explaining the "Split Injection Strategy" in HCCI}

After dealing will full load, the next step in the NADI ${ }^{\mathrm{TM}}$ concept development was to fully understand-and benefit from - the capabilities of the combustion system, in order to reduce emissions at part load. Task for which CFD came in quite handy.

Raising the EGR level (up to $50 \%$ ) has proven an effective way to control $\mathrm{NO}_{\mathrm{x}}$ emissions. In [30] it is shown that if combined with an appropriate injection strategy (the so-called "split injection strategy") one can also reduce soot emissions. Simulations were performed using the new models on such running conditions (cf. Table 2) in order to better understand why the combination of the injection strategy and the operating conditions was so beneficial. The engine used is here again a 2.21 I4 NADI ${ }^{\mathrm{TM}}$ engine (cf. Table 1 ) and the FIS characteristics are listed in Table 3. In order to ascertain the benefits of the new auto ignition model, the previous auto-ignition model - the correlation determined by Ryan \& Callahan [27, 28]—was also used. Figure 13 illustrates the fact that the old correlation which was satisfactory for small EGR rates is unable to correctly predict auto-ignition for the particular operating conditions.

TABLE 1

Engine characteristics

\begin{tabular}{c|c|c}
\hline Stroke & Bore & Compression ratio \\
\hline $92 \mathrm{~mm}$ & $87 \mathrm{~mm}$ & $14: 1$ \\
\hline
\end{tabular}

TABLE 2

High EGR rate operating conditions for a single-cylinder engine

\begin{tabular}{c|c|c|c|c|c}
\hline RPM & $\begin{array}{c}\text { Air flow rate } \\
(\mathrm{kg} / \mathrm{h})\end{array}$ & $\begin{array}{c}\mathrm{Q}_{\text {inj }} \\
(\mathrm{mg})\end{array}$ & $\lambda$ & $\begin{array}{c}\text { EGR rate } \\
\text { rate }\end{array}$ & $\begin{array}{c}\mathrm{P}_{\text {rail }} \\
(\mathrm{MPa})\end{array}$ \\
\hline 1500 & 14.3 & 19.3 & 1.14 & $54 \%$ & 140 \\
\hline
\end{tabular}

TABLE 3

Injector characteristics

\begin{tabular}{c|c|c}
\hline Nb holes & Static flow rate & Spray cone angle \\
\hline 6 & $450 \mathrm{ml} / 30 \mathrm{~s} @ 10 \mathrm{MPa}$ & $60^{\circ}$ \\
\hline
\end{tabular}

Simulation and test bench results are in agreement for this particular operating point when it comes to in-cylinder pressure and burnt mass fraction. 


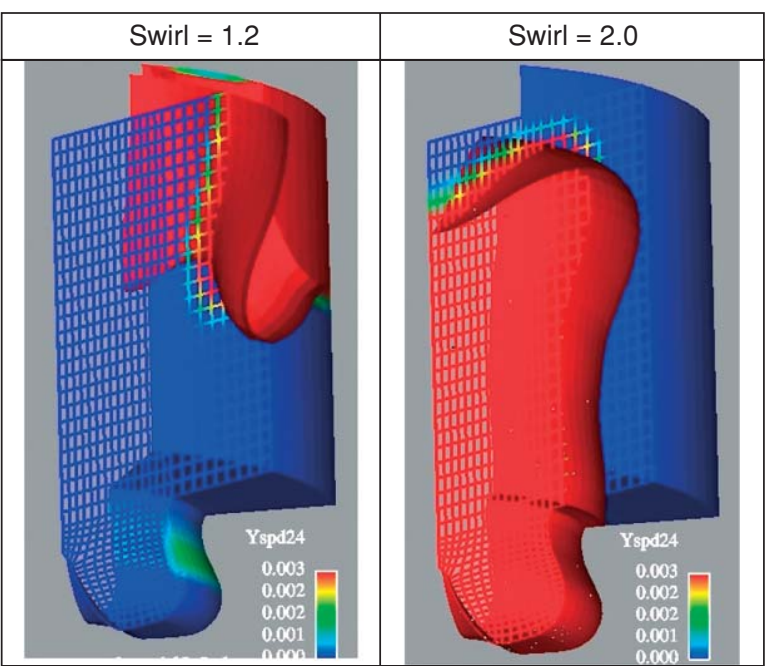

Figure 12

Soot localisation at exhaust valve opening at 4000 RPM for bowl design $\mathrm{B}$

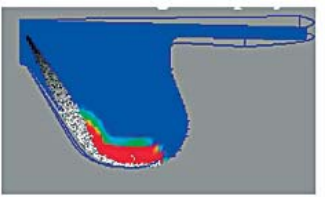

1st injection: 8 cad bTDC

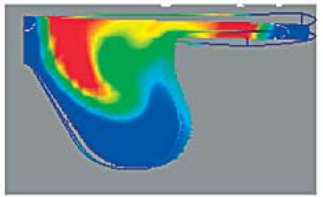

$8 \mathrm{cad}$ aTDC

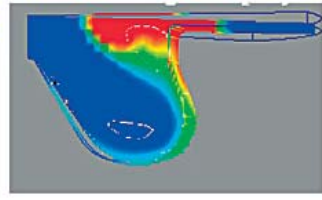

1 cad aTDC

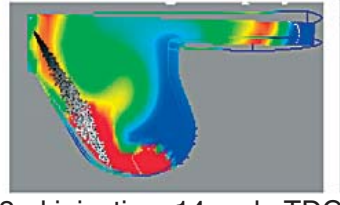

2nd injection: 14 cad aTDC

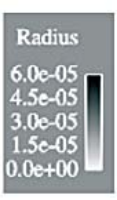

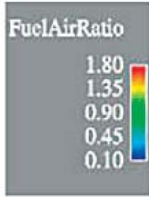

Figure 14

Injecting into fresh air thanks to the first injection vortex. Fuel to Air equivalence ratio field in a cut plane through the spray .

Such an operating point was tested using a conventional combustion system and did not give satisfactory results. The simulation helped understand why a NADITM combustion system did much better: the air entrainment, due to the vortex created by the first injection (cf. Fig. 14), brings fresh air into the bowl beneficial for the second injection, giving it ideal mixing and burning conditions. Such an air entrainment is entirely due to the NADI ${ }^{\mathrm{TM}}$ concept's narrow spray cone angle combined with the specific piston shape. This phenomenon does not occur in a conventional combustion system where the second injection takes place in already rich or even burnt mixtures.

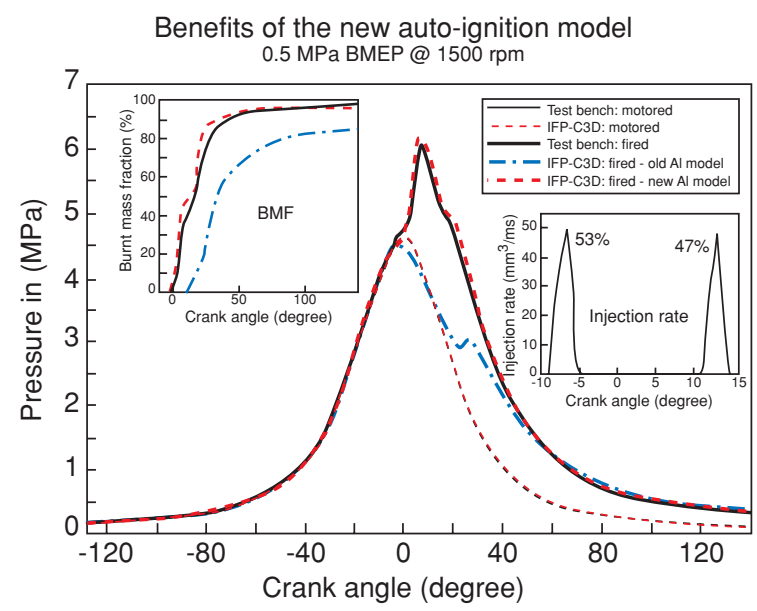

Figure 13

Comparison of computed cylinder pressures using the old auto-ignition model and the new one for HCCI combustion mode.

\section{Adapting the Split Injection Strategy to a Smaller Engine}

In the following, split injection was applied to a smaller engine using equally the NADI ${ }^{\mathrm{TM}}$ combustion concept. The interest here is to show the effect of the variation of injection parameters on combustion behavior.

Three variations have been tested. The first is a shift in injection timing, keeping the difference between SOI $_{1}$ (Start of Injection) and $\mathrm{SOI}_{2}$ constant. The second implies a relative shift of $\mathrm{SOI}_{2}$ while keeping $\mathrm{SOI}_{1}$ constant. The last case concerns a variation in mass proportions between both injections while maintaining the total injected mass.

The operating conditions for part load operation are given in Table 4. The injector is a six-hole injector with a spray cone angle of $60^{\circ}$ and a static flow rate of 380 ml/30s@10 MPa. The corresponding injection characteristics for the reference point are given in Table 5.

TABLE 4

Operating conditions for split injection

\begin{tabular}{c|c|c|c|c|c}
\hline RPM & BMEP & $\begin{array}{c}\text { Compression } \\
\text { ratio }\end{array}$ & $\lambda$ & $\begin{array}{c}\text { EGR } \\
\text { rate }\end{array}$ & $\begin{array}{c}\mathrm{P}_{\text {rail }} \\
(\mathrm{MPa})\end{array}$ \\
\hline 1500 & $7.8 \mathrm{bar}$ & $14: 1$ & 1.14 & $46 \%$ & 160 \\
\hline
\end{tabular}

TABLE 5

Injection characteristics for reference point

\begin{tabular}{c|c|c}
\hline $\begin{array}{c}\mathrm{SOI}_{1} \\
\left({ }^{\circ} \mathrm{CA}\right)\end{array}$ & $\begin{array}{c}\mathrm{SOI}_{2} \\
\left({ }^{\circ} \mathrm{CA}\right)\end{array}$ & $\begin{array}{c}\text { Mass proportions } \\
\text { between injections }\end{array}$ \\
\hline 2 & 15 & $80: 20$ \\
\hline
\end{tabular}




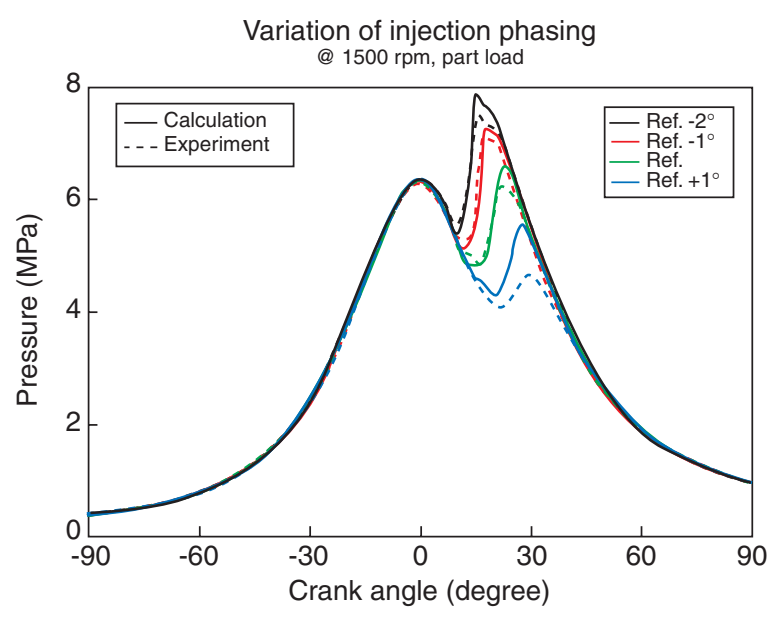

Figure 15

In-cylinder pressure for variation of injection phasing (reference case for $\mathrm{SOI}_{1}=2^{\circ} \mathrm{CA}$ )

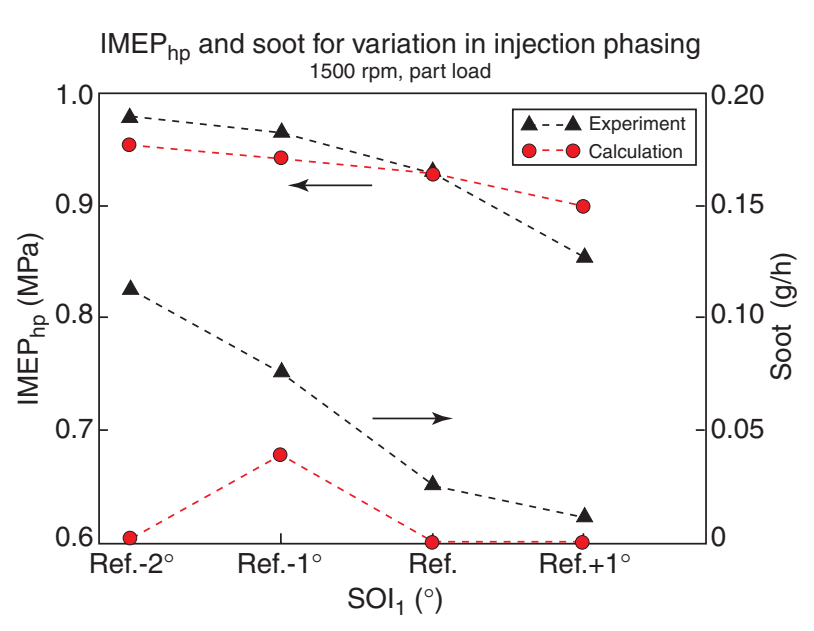

Figure 16

$\mathrm{IMEP}_{\mathrm{hp}}$ and Soot trends for variation in injection phasing.

It should be noted that in general the soot levels remain low for this operating point when using the reference injection phasing or a later injection timing.

Variation of $\mathrm{SOI}_{2}$ for constant $\mathrm{SOI}_{1}$

This variation in fact narrows and enlarges, respectively, the dwell time between two injections. It is clear that when both injections are phased close to each other, the limiting case of a single injection is obtained. As a consequence, the advantages of low soot levels and reduced noise of a split injection are lost.

Figure 17 displays the corresponding in-cylinder pressure for the experiment and the calculation. First it can be noted that the trends of a variation of $\mathrm{SOI}_{2}$ are well captured in the calculations. The proximity of the pressure histories between the reference case and the one for a $2^{\circ} \mathrm{CA}$ later $\mathrm{SOI}_{2}$ is also seen in the CFD results. The numerical results for the case with the shortest dwell time between two injections (Ref. $+6^{\circ}$ ) reach a considerably higher peak pressure compared to the other cases, as equally observed in the experiment.

When comparing the maximum in-cylinder pressure for the second peak, it can be concluded that this value is predicted within $10 \%$ with small differences already present around TDC. One reason for the discrepancies could be pressure oscillations in the rail due to split injection, which have a significant impact on the mass injected for each injection at constant total injected mass. This could potentially alter the distribution of fuel/air equivalence ratio in the bowl and combustion chamber and consequently will affect the combustion evolution. This effect has not been taken into account in the calculations due to the lack of experimental data. Taking into account the coupling between 1D injection system formation. 


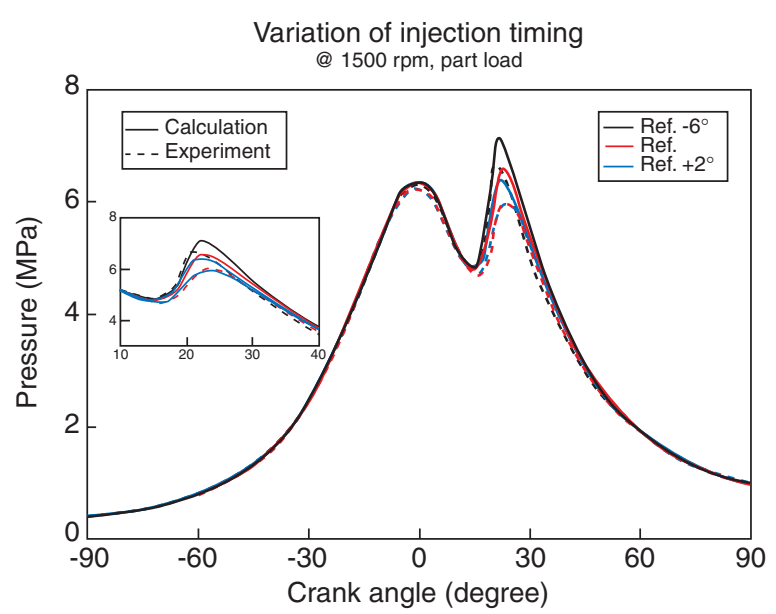

Figure 17

In-cylinder pressure for variation of injection timing for second injection (reference case for $\mathrm{SOI}_{2}=15^{\circ} \mathrm{CA}$ ).

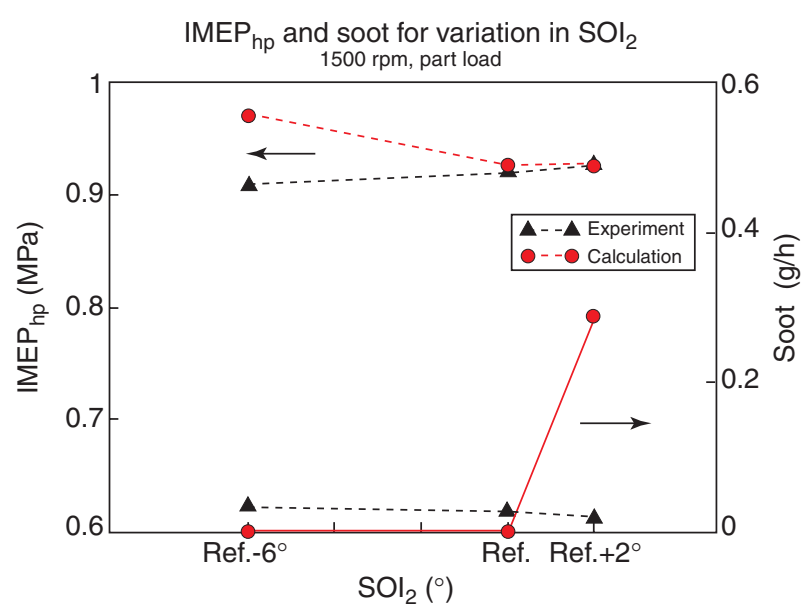

Figure 18

$\mathrm{IMEP}_{\mathrm{hp}}$ and Soot for variation in $\mathrm{SOI}_{2}$.

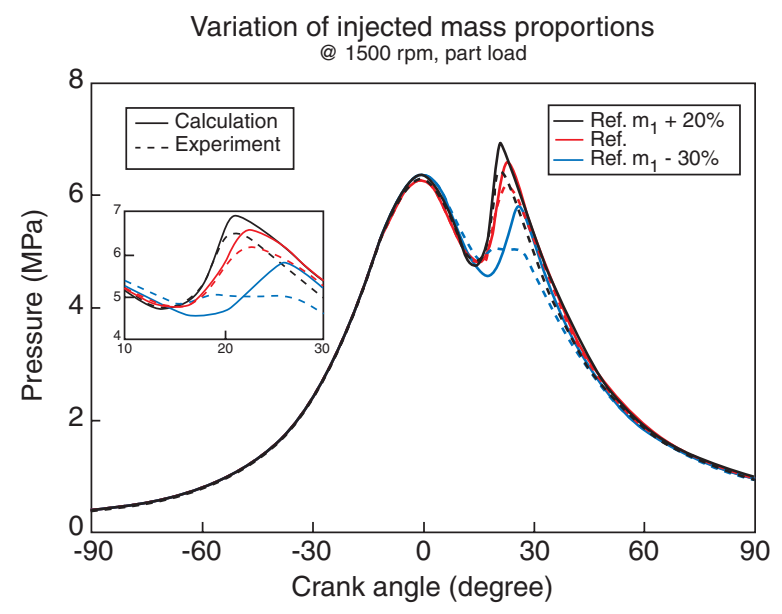

Figure 19

In-cylinder pressure for variation of injected mass proportions (reference case for $80 \%$ of mass in first injection).

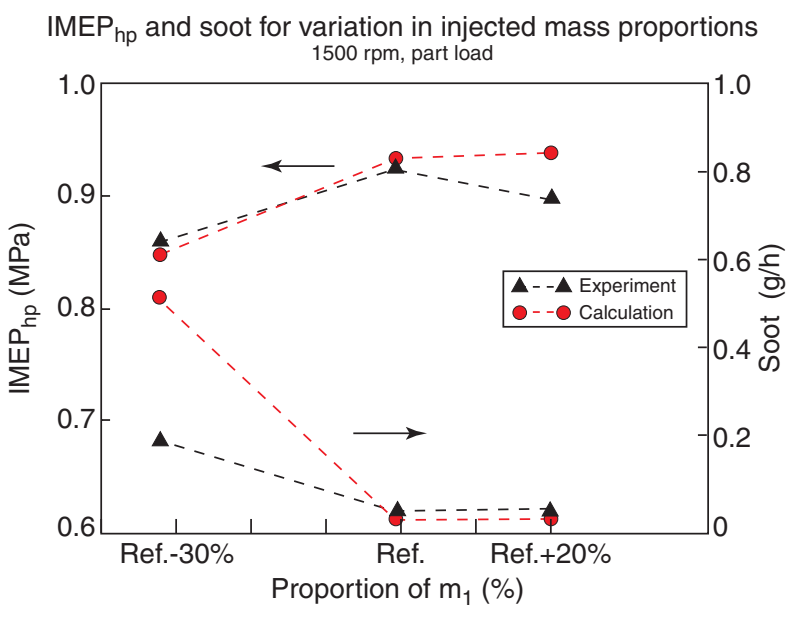

Figure 20

$\mathrm{IMEP}_{\mathrm{hp}}$ and Soot for variation of injected mass proportions. simulations and 3D combustion simulations should allow to improve the results and provide valuable information about the abovementioned uncertainties. Given this uncertainty, the numerical results are encouraging.

The trends for $\mathrm{IMEP}_{\mathrm{hp}}$ and soot are shown in Figure 18. Regarding the $\mathrm{IMEP}_{\mathrm{hp}}$ it is seen that the predicted values agree well with the experiments, except for the case with the shortest dwell time. For soot, an increase is observed in the CFD results for larger $\mathrm{SOI}_{2}$. A closer look at the $3 \mathrm{D}$ results reveals that in those cases the second injection injects into the mixture formed from the first injection. Therefore the recirculated air pocket is not utilized, creating locally very rich conditions. In the test bench results this situation is, however, seemingly not encountered for the same operating point, giving lower soot emissions. The discrepancies might again be linked to the uncertainty in injected mass for each injection.

To estimate the impact of a variation of mass proportions on combustion, the next variation has been performed.

Variation of injected mass proportions for constant total injected mass

Changing the mass proportion of the first injection will strongly influence the air movement in the bowl and therefore the position of the air pocket into which the second injection should preferably inject. 


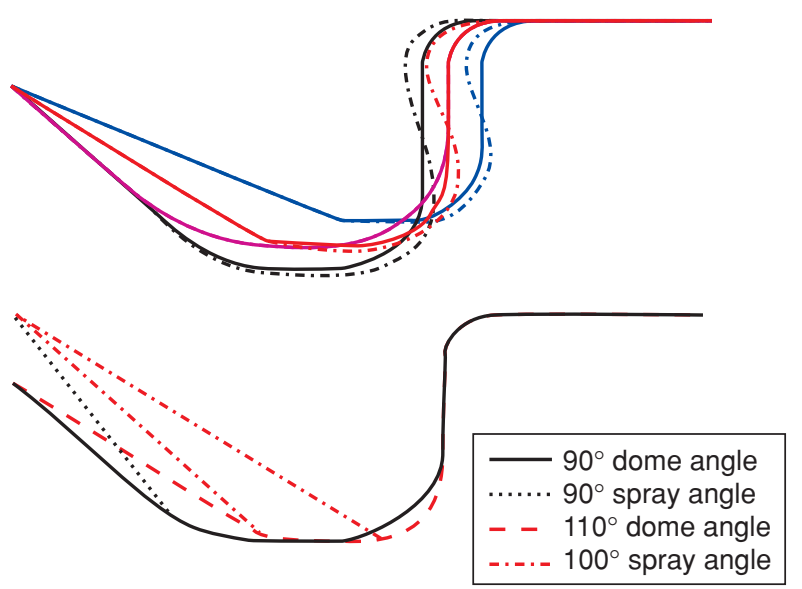

Figure 21

$\mathrm{NADI}^{\mathrm{TM}}$ bowls tested and configurations selected after full load investigations.
B25 (5 bar IMEP @ 1500 rpm)

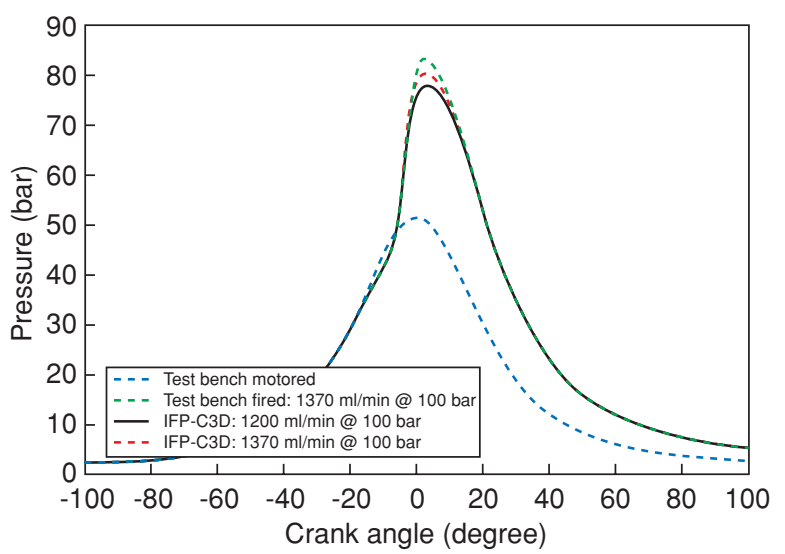

Figure 22

Validation of HCCI investigations.
The comparison of the in-cylinder pressure between experiment and calculation is given in Figure 19. While the numerical results for the reference case and the case with a higher mass for the first injection correlate better with the experiments, the third case for a reduction of the first injected mass shows clear differences. On the test bench the autoignition delay seems shorter, even shorter than for the other test cases, followed by a small, yet visible, heat release from $10^{\circ}$ to $15^{\circ} \mathrm{CA}$. Thereafter the combustion is possibly calmed down by the effects of the second injection, featuring a significantly higher mass proportion than for the other cases. The clearly shorter experimental ignition delay for the third case compared to the other cases cannot be fully explained and remains within the experimental uncertainty. The CFD results, on the contrary, give consistently a longer ignition delay when the first injected mass is reduced.

The impact of the variation of mass proportions on $\mathrm{IMEP}_{\mathrm{hp}}$ and soot is shown in Figure 20. Both trends are well reproduced numerically and are a result of the interaction in the bowl of the fuel-rich areas due to both injections and the air pocket. A reduced first injected mass will slow down the recirculation in the bowl, such that, when keeping the same injection timing, the second injection injects into the rich mixture. This will induce high soot levels and consequently a lower power output.

\section{Conclusions}

The variations for split injection sensibly show the effect of injection characteristics on mixture preparation and on combustion. The experimental trends can be reproduced quite satisfactorily. It is demonstrated that the NADI ${ }^{\mathrm{TM}}$ combustion concept is capable of reaching low soot levels for a part load operating point by choice of an adapted set of injection parameters.

\section{Adapting the NADI ${ }^{\mathrm{TM}}$ Concept to Heavy Duty}

Developed on passenger car applications, the NADI ${ }^{\mathrm{TM}}$ concept was conceived as a more general concept applicable to any Diesel engine. Its potential was so appealing that it was not long before a project intended at developing clean heavy duty engines decided to try it out. The engine used in the study is a 7.8 liter I6 engine whose characteristic can be found in CFD was put to contribution in order to accelerate the adaptation of passenger car know-how to heavy duty engines. Such an adaptation was carried out by widening of the piston bowl and injector spray cone angle. Several bowls and corresponding injection systems were tested.

At full load, configuration selection was based on power requirements, the NADI ${ }^{\mathrm{TM}}$ chamber with a compression ratio of 14:1 having to provide as much power as the original chamber (compression ratio of 17:1) without any fuel consumption penalty and with a peak pressure limit of 200 bar. After few CFD iterations, 2 bowls were selected: one for best power compromise and the other for compatibility with available injectors as illustrated in Figure 21. The next selection criterion was emissions levels at part load. An operating point was chosen and injection strategies tested on the selected bowls. Results showed that HCCI combustion was favored by the configuration with the narrowest spray cone angle, indicating that an ideal optimum would need to be found between full load (wider) and part load (narrower) configurations. The narrow configuration was manufactured for test bench investigations. 
All previous HCCI combustion CFD work was performed without any test bench data. Once the selected configuration was manufactured and test bench available a validation of the previous CFD work was performed by computing a test bench HCCI operating point described in. Results are illustrated in Figure 22 and confirm the confidence put in the CFD tools for piston bowl pre-design for part load HCCI operating conditions. Two CFD cases are presented: one for the theoretical injector static mass flow rate and one with the effective injector static mass flow (that measured on the injector test bed after manufacturing: 1370 ml/min@100 bar).

\section{TABLE 6}

High EGR rate operating conditions for a single-cylinder engine

\begin{tabular}{c|c|c|c|c|c}
\hline Rpm & IMEP & $\begin{array}{c}\text { Compression } \\
\text { ratio }\end{array}$ & $\lambda$ & $\begin{array}{c}\text { EGR } \\
\text { rate }\end{array}$ & $\begin{array}{c}\mathrm{P}_{\text {rail }} \\
(\mathrm{Mpa})\end{array}$ \\
\hline 1580 & 5 bar & $14: 1$ & 1.25 & $55.4 \%$ & 140 \\
\hline
\end{tabular}

\section{CONCLUSION}

This paper has shown some recent progress in CFD tools in terms of spray, auto-ignition and combustion models. All these developments and those to come are motivated by the rapid evolutions of the Diesel engine technology, and the need to keep in pace with test bench developments and needs. Tests have shown that without these improvements the use of older models would have proven blatantly inaccurate for certain operating points whatever the configuration considered. In particular it was shown that early pilot injections in conventional engines and high EGR HCCI combustion could only be accurately accounted for thanks to the new auto-ignition model.

We have shown how CFD tools are integrated in the Research \& Development chain and how the latest models and their accuracy have been used to understand and optimise conventional, near-future and prospective configurations. Such configurations are varied as we have shown:

- Piston bowl design and optimal fluid motion for the NADI ${ }^{\mathrm{TM}}$ concept at full load.

- Mixture formation and combustion for the NADITM concept in HCCI mode.

This shows the flexibility and adaptability of the CFD tools developed at IFP, which contribute to the progress of the Diesel engine.

\section{ACKNOWLEDGEMENTS}

The authors would like to thank the Groupement Scientifique Moteur (GSM) for supporting some physical submodel developments and the European Commission for supporting HCCI combustion research through European Projects.

\section{REFERENCES}

1 Wang T.C., Han J.S., Xie X.B., Lai M.C., Henein N.A., Schwarz E. and Bryzik W. (2000) Parametric characterization of high pressure Diesel fuel unit injection systems. ASME paper 2000-ICE-281.

2 Blessing M., König G., Krüger C., Michels U. and Schwarz V. (2003) Analysis of Flow and Cavitation Phenomena in Diesel Injection Nozzles and its Effects on Spray and Mixture Formation. SAE paper 2003-01-1358.

3 Marcer R., Le Cottier P., Chaves H., Argueyrolles B., Habchi C. and Barbeau B. (2000) A Validated Numerical Simulation of Diesel Injector Flow Using a VOF Method. SAE paper 2000-01-2932.

4 Habchi C., Dumont N. and Simonin O. (2003) CAVIF: A 3D Code for the Modeling of cavitating Flows in Diesel Injectors. ICLASS 2003, Sorrento ITALY.

5 Béard P. (2005) Towards a Predictive Modelling of Transient Injection Conditions of Diesel Sprays in DID Engines, ILASS America 18th Annual Conference on Liquid Atomization and Spray Systems, Irvine, CA, May 2005.

6 Pires da Cruz A. (2004) Three-Dimensional Modeling of Self-Ignition in HCCI and Conventional Diesel Engines, Comb. Science and Tech. 176, 5-6, 867-887.

7 Jay S. and Colin O. (2005) Fuel composition influence on auto-ignition in engine 3D simulations, 20th ICDERS, Montréal.

8 Lutz A., Kee R. and Miller J. (1987) Senkin: A Fortran program for predicting homogeneous gas phase chemical kinetics with sensitivity analisys, Report No. SAND87-8248.UC-4, Sandia National Laboratories.

9 Kee R.J., Rupley F.M. and Miller J.A. (1989) Chemkin-II: A Fortran chemical kinetics package for the analysis of gasphase chemical kinetics, Report No. SAND89-8009.UC401, Sandia National Laboratories.

10 Buda F., Bounaceur R., Warth V., Glaude P.A., Fournet R. and Battin-Leclerc F. (2005) Progress towards a unified detailed kinetic model for the autoignition of alkanes from $\mathrm{C} 4$ to $\mathrm{C} 10$ between 600 and $1200 \mathrm{~K}$, Combust. Flame, 142, 1-2, 170-186.

11 Zolver M., Torres A. and Klahr D. (2001) CFD and Combustion in Engines with an Unstructured Parallel Solver Based on KIVA. Article (1-14), The Fifth International Symposium on Diagnostics and Modeling of Combustion in Internal Combustion Engines, COMODIA 2001, July 2001, Nagoya, Japan.

12 Zolver M., Torres A. and Klahr D. (2002) An Unstructured Parallel Solver for Engine Intake and Combustion Stroke Simulation. SAE paper 2002-01-1120.

13 Zolver M., Klahr D., Bohbot J., Laget O. and Torres A. (2003) Reactive CFD in Engines with a New Unstructured Parallel Solver. Oil \& Gas Science and Technology, 58, ${ }^{\circ} 1$, 33-46.

14 Bohbot J., Klahr D., Zolver M. and Torres A. (2003) A Three Dimensional Modelling of Combustion in a Direct Injection Diesel Engine using a New Unstructured Parallel Solver. The 2003 International Conference on Computational Science and its Applications, ICCSA, May 2003, Montréal, Canada, proceedings, 483-492.

15 Zolver M., Bohbot J., Klahr D. and Torres A. (2003) An Unstructured Parallel Solver for Multi-phase and Reactive Flows in Internal Combustion Engines. Parallel CFD 2003, Mai 2003, Moscow.

16 Zolver M., Benkenida A., Bohbot J., Klahr D. and Réveillé B. (2004) CFD Tools at IFP for HCCI Engine Simulations. 
International Multidimensional Engine Modelling User's Group Meeting, March 2004, Detroit, USA.

17 Béard P., Duclos J.M. and Zolver M .(2001) Modélisation de la combustion Diesel - Rapport des activités 2000. Technical Report 55913, IFP.

18 Béard P., Colin O. and Miche M. (2003) Improved Modelling of DI Diesel Engines Using Sub-grid Descriptions of Spray and Combustion. SAE paper 2003-01-0008.

19 Béard P., Duclos J.M., Habchi C., Bruneaux G., Mokkadem K. and Baritaud T. (2000) Extension of Lagrangian-Eulerian Spray Modelling: Application to high pressure Evaporating Diesel Sprays. SAE paper 2000-01-1893.

20 Colin O., Benkenida A. and Angelberger C., 3D Modelling of Mixing, Ignition and Combustion Phenomena in Highly Stratified Gasoline Engine. Oil \& Gas Science and Technology, 58, 1, 2003.

21 Colin O. and Benkenida A. (2004) The 3-Zones Extended Coherent Flame Model (ECFM3Z) for computing premixed diffusion combustion. Oil \& Gas Science and Technology, $\mathbf{5 9 ,} 6,2004$.

22 Magnussen B.F. and Hjertager B.H. (1976) On Mathematical Modelling of Turbulent Combustion with Special Emphasis on Soot Formation and Combustion. In 16th Symposium (International) on Combustion, 719-729. The combustion Institute.

23 Martinot S., Béard P., Roesler J. and Garo A. (2001) Comparison and coupling of homogeneous reactor and flamelet librariy soot modeling approaches for Diesel combustion. SAE paper 2001-01-3684

24 Bensler H., Buhren F., Samson E. and Vervish L. (2000) 3D CFD Analysis of the Combustion Process in a DI Diesel Engine Using a Flamelet Model. SAE paper 2000-01-0662.

25 Heywood J.B. (1988) Internal Combustion Engine Fundamentals. McGraw Hill.

26 http://www.amesim.com, IMAGINE.

27 Ryan T.W. and Callahan T.J. (1988) Engine and constant volume bomb studies of Diesel ignition and combustion. $S A E$ technical paper 881626.

28 Ryan T.W. and Callahan, T.J. (1996) Homogeneous Charge Compression Ignition of Diesel fuel. SAE paper 961160.

29 Colin O., Pires da Cruz A. and Jay S. (2005) Detailed chemistry based auto-ignition model including low temperature phenomena applied to 3D engine calculations. Proc. Combust. Inst. 30, 2, 2649-2656.

30 Walter B., Monteiro L., Miche M and Gatellier B. (2004) Improvment of Exhaust and Noise Emissions of the NADI ${ }^{\mathrm{TM}}$ concept using pre-mixed type combustion with multiple stages injection. The Diesel Engine: TODAY and TOMORROW, SIA 2004. 